\title{
Desafios da investigação com crianças na formação de professores: contributos da sociologia da infância
}

Ana Cristina Palos ${ }^{1}$

\section{Resumo}

Em sintonia com um quadro teórico que se vem afirmando desde os anos 70 do século $\mathrm{XX}$, a formação de professores, desenvolvida em diversos países, constrói-se em torno de estratégias formativas assentes em dinâmicas de investigação. A investigação com crianças, enquanto sujeitos de aprendizagem, tem ocupado um lugar privilegiado nesta estratégia formativa encetada na Universidade dos Açores, e, em algumas unidades curriculares, os quadros concetuais da Sociologia da Infância contribuem para que os formandos compreendam a alteridade infantil e incorporem esse conhecimento na ação pedagógica. No presente artigo, prioriza-se a descrição e a análise de situações reais, que envolveram formandos e formadores da universidade, como mote para discutir os desafios que podem ocorrer na relação que o investigador e as crianças constroem no decurso dos processos de investigação, refletindo alguns dos fatores relacionais e contextuais que podem complexificar esse processo. Entre os múltiplos desafios, destacam-se a forma como as imagens que a sociedade constrói sobre a infância podem condicionar a relação investigador-criança e os obstáculos que o desempenho do ofício de aluno criam à livre expressão da identidade das crianças; reflete-se, ainda, a forma como os adultos que, no contexto escolar, controlam o acesso do investigador aos contextos, podem condicionar o conhecimento que se pretende construir sobre as crianças. Conhecimento este que é desafiado permanentemente pela incompetência do adulto que desconhece manifestações das culturas infantis.

\section{Palavras-chave}

Investigação com crianças - Sociologia da infância - Crianças - Professor investigador.

1- Universidade dos Açores, Ponta Delgada, Açores, Portugal. Contato: ana.cp.palos@uac.pt 


\section{Challenges of researching children in teacher education: contributions from Sociology of Childhood}

In many countries, in line with a theoretical framework that has gained prominence since the 1970s, teacher education has been centered around research-based formative strategies. Research involving children as learning subjects has played a crucial role in the training model adopted by the University of Azores, and in some curricular units, the conceptual frameworks in Sociology of Childhood contribute to the students' understanding of the otherness of childhood and to absorbing this understanding into their pedagogical action. This article focuses on the description and analysis of real situations in which students and university professors were involved and uses them as a starting point to discuss the challenges arising from the relationship that researchers and children establish, reflecting on relational and contextual factors that can make this process more complex. The many challenges include the way in which the images of childhood, created by society, can influence the researcher-child relationship and produce obstacles to the free expression of a child's identity. We also reflect on how adults who control the access of researchers to different school contexts can affect the knowledge on children that we aim to assemble, a knowledge that is permanently challenged by the incompetence of adults who ignore how infant cultures manifest themselves.

\section{Keywords}

Research on/with children - Sociology of childhood - Children - Teacher as a researcher.

\section{Introdução}

A partir dos anos 70 do século XX, ganham força, nas ciências da educação, os paradigmas de formação de profissionais do ensino que procuram induzir uma cultura de investigação nas escolas do ensino não superior. 0 conceito de professor investigador, desenvolvido na obra pioneira de Stenhouse (1975), apela ao professor como construtor de conhecimentos e promove a ideia de que a investigação-ação é o método por excelência, questionando, desta forma, conceções que reduzem a atividade docente à mera aplicação técnica de conhecimentos científıcos produzidos por especialistas.

$\mathrm{Na}$ generalidade das instituições portuguesas, a formação inicial de educadores de infância e professores tem implementado planos curriculares nos quais a investigação assume centralidade. No caso particular da Universidade dos Açores, essa inclusão está presente desde a criação dos cursos de formação de inicial, mas tem vindo a aprofundar-se pela reestruturação dos mesmos na linha do Processo de Bolonha, enquanto processo de criação de um Espaço Europeu do Ensino Superior. 
Conscientes de que a simples inclusão de unidades curriculares não garante a assunção de uma dimensão investigativa na construção da profissionalidade docente, os esforços formativos procuram garantir que os formandos compreendam o papel da investigação na construção das práticas educativas, lugarizando nos planos curriculares oportunidades de mobilização de conhecimentos sobre pesquisa em contextos de iniciação à prática profissional e de prática educativa supervisionada (SOUSA; PALOS, 2014).

A primazia concedida à participação dos formandos na construção de conhecimento na área científica em que se estão a formar inclui um conhecimento aprofundado e contextualizado das próprias crianças enquanto sujeitos de aprendizagem, tornando-os conscientes de que a ideia de criança universal é uma abstração construída por modelos pedagógicos pré-estruturados assentes em propostas teóricas e pedagógicas que se fundam num sistema articulado de pressupostos sobre o que é uma criança.

No sentido de ultrapassar as limitações decorrentes dessas diretrizes educacionais de pendor universalista, a formação de professores na Universidade dos Açores procurou, desde cedo, privilegiar o estudo da "realidade concreta das crianças" (SARMENT0, 2013, p. 132), criando a oportunidade para que os formados pudessem, em uma perspetiva de investigação, compreender as singularidades das suas formas de ser e estar, bem como as suas caraterísticas sociais e culturais específicas, e incorporar esse conhecimento sobre a alteridade infantil na ação pedagógica.

Foi neste contexto ${ }^{2}$ que surgiu a oportunidade de orientar vários trabalhos de investigação que procuravam compreender as perspectivas das crianças, considerando-as como os informantes privilegiados e os mais qualificados para se encetar um percurso de desocultação das suas experiências nos diversos contextos sociais de referência.

As problemáticas debatidas neste artigo são, em grande parte, devedoras dessa gratificante experiência de formação ${ }^{3}$ e refletem os dilemas e os desafios da investigação realizada junto a crianças reportados pelos próprios formandos e que, enquanto formadora, testemunhamos, quer nas atividades de orientação quer nas investigações em que tivemos oportunidade de participar em coautoria.

Essas incursões nos universos infantis foram sustentadas nos desenvolvimentos teóricos e metodológicos da Sociologia da Infância. Como refere Sirota (2006), até os anos 80 , do século XX, as práticas infantis pareciam reféns de uma invisibilidade e a criança era uma personagem fantasma relativamente ausente das problemáticas, quer da Sociologia da Educação quer da Sociologia da Família, onde imperava o ponto de vista dos adultos responsáveis pela sua socialização.

De forma inversa, a Sociologia da Infância perspectiva que as crianças são "atores sociais com as suas próprias experiências" e formas de perspectivar o mundo (CHRISTENSEN; PROUT, 2002, p. 481), mudando e sendo modificadas pelos

\footnotetext{
2- Entre 2003 e 2009, a investigação com crianças ocorreu na disciplina anual de Seminário, do $4^{\circ}$ ano do curso de Licenciatura em Educação de infância. Entre 2009 e 2013, ocorreu no âmbito da disciplina de Infância e perspetivas sobre o mundo, optativa, incluída no $2^{\circ}$ ano da licenciatura em Educação Básica.

3- Agradecemos às alunas e aos alunos a oportunidade que nos deram de trilhar com eles estes percursos de descoberta de múltiplas formas de ser criança.
} 
contextos culturais e sociais em que vivem (CORSARO, 1997). Sendo produtoras de culturas específicas, elas são, simultaneamente, intérpretes competentes da sua própria experiência social o que implica, como refere James (2007), considerar que as suas perspectivas são centrais na compreensão e teorização acerca dos seus mundos sociais e uma investigação que priorize as perspectivas infantis tem de captar as suas "ações sociais, o seu uso da linguagem e os significados que elas colocam nas palavras, crenças e ações" (CHRISTENSEN; PROUT, 2002, p. 482).

São inúmeros os desafios que se colocam ao processo de investigação quando perspetivamos os mais novos como sujeitos de conhecimento e reconhecemos a legitimidade das suas formas de significação sobre o mundo. Este artigo centra-se na análise de alguns dos desafios que podem ocorrer na relação que o investigador e as crianças constroem no decurso dos processos de pesquisa, discutindo alguns dos fatores que podem complexificar tal processo.

Em síntese, são quatro os objetivos que nos orientam: (1) discutir em que medida as imagens que a sociedade formula sobre as crianças podem condicionar o processo de investigação e a forma como essas se dão a conhecer ao investigador; (2) evidenciar tensões que podem surgir quando se procura desocultar as vozes das crianças habituadas ao desempenho do ofício de aluno; (3) refletir em que medida os adultos que controlam o acesso à criança, designadamente em meio escolar, podem condicionar esses processos de investigação; e (4) refletir situações que, na investigação, desafiam a (in)competência do investigador que desconhece manifestações das culturas infantis.

Para situar a forma como os dados que são apresentados e discutidos neste artigo foram produzidos, começamos por apresentar uma nota metodológica.

\section{Nota metodológica}

A reflexão que aqui apresentamos, acerca dos dilemas e desafios que se colocam nas investigações com crianças, baseia-se em três investigações que foram desenvolvidas no âmbito da formação inicial de professores na Universidade dos Açores.

0 primeiro estudo (E1) está focado no ponto de vista das crianças acerca da forma como a escola e a família consideram as suas opiniões e os mecanismos utilizados para as envolverem nas decisões que as implicavam. A investigação, desenvolvida entre outubro de 2011 e fevereiro de 2012, foi realizada junto a 30 alunos, com idades compreendidas entre os 8 e os 10 anos de idade, de uma escola do $1^{\circ}$ ciclo do ensino básico em uma freguesia da Ilha Terceira, Açores (PALOS; SOUSA, 2012). 0 segundo (E2) foi desenvolvido por um grupo de formandas da licenciatura em educação de infância e procurou apreender as perspectivas de crianças de 5 anos de idade acerca das brincadeiras, em duas escolas infantis da ilha, tendo sido observadas, durante o ano letivo de 2004/2005, 44 crianças. Já o terceiro estudo (E3), em que estiveram envolvidas 22 crianças, foi desenvolvido, no ano letivo de 2010/2011, no âmbito da licenciatura em educação básica, por um grupo de formandas que procuravam analisar as relações de gênero entre crianças de 5 anos de idade em uma escola infantil da ilha. 
Em qualquer um dos estudos, os instrumentos de recolha de dados incluíram, para além dos desenhos realizados pelas crianças, entrevistas semiestruturadas e observações diretas registradas em cadernos de campo que, depois de organizados e sistematizados em termos cronológicos e temáticos, deram origem aos diários de campo (LEAL, 2016).

A transcrição dos depoimentos foi norteada pelo respeito integral da estrutura e formas discursivas utilizadas, quer pelos investigadores, quer pelas crianças. Em face do material empírico proveniente desses diferentes instrumentos de pesquisa, e após uma análise vertical e horizontal do mesmo, elaboramos grades temáticas em que procuramos uma redução e sistematização dos dados que nos permitissem uma leitura sincrônica do corpus empírico proveniente das entrevistas, dos diários de bordo e dos diálogos estabelecidos com as crianças durante a realização dos desenhos.

Ao adotar os procedimentos característicos das análises de conteúdo temáticas, ou categoriais, construímos sistemas de codificação dos dados para permitir a clarificação do material recolhido em função dos campos semânticos delimitados. Para o efeito, elaboramos fichas separadas por temas (no programa Excel) transcrevendo, para cada tema, os excertos de depoimento correspondente, procurando manter o discurso tal como foi produzido pelas crianças. De notar que os temas de análise, ou unidades significativas, são, como refere d'Unrug (citada por Bardin, 1979), unidades de "comprimento variável" cuja "validade não é linguística mas psicológica: podem constituir um tema tanto uma afirmação como uma alusão” (BARDIN, 1979, p. 105).

As categorias foram construídas com base em dois processos: um que derivou dos enunciados teóricos (categorias a priori) e outro que brotou da própria natureza dos dados recolhidos (categorias a posteriori). No sentido de pugnar pela validade interna do sistema de categorias construído, procuramos assegurar que todas as unidades de registo tinham sido colocadas em uma categoria - exaustividade - que cada uma delas incluía, apenas, uma unidade de registro - exclusividade - e que os critérios de categorização se mantinham ao longo do processo de codificação - homogeneidade (BARDIN, 1979; ESTEVES, 2006).

Procuramos garantir, nesse sistema de categorias construído, quer a fiabilidade intracodificador - garantir a estabilidade do sistema de categorias para um codificador em diferentes momentos de análise - quer a fiabilidade intercodificadores - fazendo intervir diferentes juízes (formadores e formandos) na apreciação de um sistema de categorização previamente estabelecido por um dos investigadores (LIMA, 2013).

Em todas as fases da pesquisa foram observados princípios éticos, designadamente o consentimento informado - por parte das crianças, pais e professores - bem como a garantia de anonimato, confidencialidade e de uso exclusivo dos dados recolhidos para efeitos acadêmicos e científicos.

\section{Impacto das imagens sociais sobre a criança no processo de pesquisa}

Apesar dos progressos societais em matéria de proteção das crianças e de reconhecimento dos seus direitos sociais, impulsionados, em grande medida, por políticas 
públicas direcionadas para a infância e a proclamação da Convenção dos Direitos das Crianças (1989), o estatuto que estas têm vindo a assumir nos estudos sociais sobre a infância ainda não contaminou muito do pensamento social que sobre elas é formulado ou as práticas sociais em que se encontram envolvidas em diferentes contextos. Como refere Sarmento (2005, p. 368), as imagens sociais sobre a infância refletem uma "negatividade constituinte" que acentua a sua subalternidade em relação aos adultos e a sua menoridade e imaturidade.

Como alguns autores têm destacado (SARMENTO, 2005; TOMÁS, 2014), as posições paternalistas sedimentam esta ideia de menoridade, assumindo-se o adulto como o intérprete legítimo dos interesses das crianças, reclamando plenos direitos sobre estas a pretexto de que são ainda imaturas e incapazes de decidirem por si próprias.

0 movimento de sentimentalização da infância, que se inicia com a descoberta da infância, como bem demonstra Ariès (1960), associado à privatização da vida familiar, criam as condições necessárias para a familiarização e institucionalização das crianças, ou seja, o confinamento da sua existência social à família e à escola; a pretexto da proteção e do reconhecimento da sua inocência e vulnerabilidade, são separadas do mundo adulto e o seu relacionamento com a sociedade mais vasta torna-se invisível (BRANNEN; 0'BRIEN, 1996).

Não escamoteamos, no sentido de Sarmento (2005), que esse controle social sobre a infância permitiu assegurar medidas de proteção e segurança sem precedentes, construir políticas sociais mais robustas no apoio à família e consolidou a ideia da criança como um projeto familiar baseado na afetividade. Mas, simultaneamente, esta proteção e controle acentuam a imagem das crianças como objetos de socialização e de educação, como seres incapazes e impreparados para a vida social, condição que contribui para provocar o "silenciamento das suas competências e capacidades" (QVORTRUP, 2010, p. 33) e para produzir sobre elas um pensamento social em que "proteção e participação são colocadas em contradição (QVORTRUP, 2010, p. 34).

Em que medida as imagens sociais de menorização da criança podem influenciar os processos de investigação e constituir um desafio para o investigador e para a relação que estabelece com ela?

Tratando-se de imagens interiorizadas culturalmente, e por isso nem sempre conscientes, é necessário que o investigador assuma uma postura de vigilância crítica e coloque em suspenso estas "pré-construções vulgares e princípios geralmente aplicados nessas construções” (BOURDIEU, 1989, p. 49), refletindo em que medida as posições paternalistas ou protecionistas, socialmente vulgarizadas, influenciam-no na forma como perspectiva as crianças, questiona-as, escuta-as e interpreta-as.

Por outro lado, não negligenciamos, na linha de Graue e Walsh (2003), que a forma como os adultos refletem as crianças em uma determinada sociedade são indicadores do que estas pensam de si mesmas. Tal fato tornou-se bem evidente na investigação que realizamos em uma escola do ensino básico (E1). Das trinta (30) crianças entrevistadas, apenas seis (6) assumiram ser ouvidas e participar nas decisões. Quando indagamos as razões que, na sua opinião, justificavam a desvalorização da sua voz, percebia-se a ausência do seu reconhecimento enquanto ator social, na linha do que temos vindo a referir: 
A4- [...] porque se calhar eu tenho poucas ideias! Às vezes eu digo as coisas e os adultos não aceitam.

A24- [...] às vezes digo coisas os adultos dizem que são sem sentido e depois ignoram-me.

A26- [...] às vezes os adultos ouvem-nos, mas só quando lhes interessa!

Esses exemplos demonstram bem como a condição infantil pode ser vivida como uma experiência estigmatizante (JAMES, 2007) e como as opiniões dos mais novos são desrespeitadas, desqualificadas e desvalorizadas, comprovando os argumentos avançados e interiorização pela própria criança da incompetência que o adulto lhe reconhece. Por outro lado, temos notado que a ausência de uma cultura de participação e de escuta ativa das crianças nas instituições que as enquadram constituem, não raras vezes, fatores inibidores da livre expressão das suas identidades e do seu envolvimento descomprometido no próprio processo de investigação, tanto mais pressentido quanto mais longa é a marcha que trilham na escolaridade (PERRENOUD, 1995), ou seja, quando atingem níveis de escolaridade mais elevados.

Importa agora refletir o impacto que esse papel de aprendente pode ter no processo de investigação e na relação da criança com o próprio investigador.

\section{O ofício de aluno como obstáculo à expressão da identidade da criança}

A escola que hoje conhecemos, apesar das modificações que nela se têm operado nas últimas décadas, mantém a forma escolar convencional (VINCENT, LAHIRE; THIN, 1994; MAULINI, MEYER; MUGNIER, 2014), enquanto modo dominante de socialização dos mais jovens que se carateriza pela "criação de um espaço-tempo especificamente consagrado à aprendizagem, separado das práticas sociais para as quais deverá preparar" (MAULINI; PERRENOUD, 2005, p. 147).

A expressão ofício de aluno (SIROTA, 1993; PERRENOUD, 1995) define a condição social da criança enquanto aprendente, em que é orientada para construir uma relação específica com a aprendizagem, que, para além de ocorrer em um espaço e em um tempo determinado, privilegia a cultura escrita, saberes objetivados, e exige uma estruturação cognitiva (LAHIRE, 1997) que pressupõe capacidade de abstração, uma relação particular com a linguagem e uma disciplina na organização e gestão do tempo e do trabalho, entre outros.

Pontuam igualmente como traços caraterizadores desta forma escolar a uniformização curricular e dos processos de ensino. A implementação de um "currículo tamanho único pronto a vestir" (FORMOSINHO, 1988) ou processos educativos que procuram "ensinar a todos como se fossem um só" (BARROSO, 2005) são outros dos princípios fundadores da escola na modernidade e que traduzem, de forma clara e sugestiva, o daltonismo desse universo às disposições individuais, ao contexto e às pertenças culturais e de classe dos alunos que acolhe.

Este modelo dominante de escolarização tem vindo a revelar, nas sociedades atuais, a sua precocidade. Com efeito, a hegemonia da escola tende a contaminar a própria 
educação das crianças entre os 3 e os 6 anos de idade, pois, como refere Cardona (2011), para o caso português, a opção pela designação educação pré-escolar pode apelar e justificar a priorização de funções de preparação para a escolaridade em detrimento de uma função educativa, cultural e social que está originalmente presente na gênese da educação de infância. Neste, como noutros níveis do sistema educativo, o monopólio educativo da escola afırma-se também com a desvalorização progressiva de outros contextos educativos informais.

Mas nas sociedades contemporâneas, a erosão dos fundamentos da modernidade tem contribuído para uma reinvenção desse ofício de aluno (SARMENT0, 2011). Como faz notar o autor, o "individualismo institucionalizado", que carateriza a sociedade atual, coloca nos indivíduos a exigência de decidir, definir estratégias, formalizar escolhas, projetar o futuro e construir a sua biografia (BECK, 2000). São múltiplos os efeitos perversos dessa normatividade, em que a fragilização dos laços sociais acompanha processos de responsabilização individual que transformam os "vencidos" do sistema em "autores" dos seus próprios fracassos (DUBET; MARTUCCELLI, 1996).

Mas essa retórica da individualização pode traduzir-se, do ponto de vista da educação escolar das crianças, em mandatos paradoxais, pois se, por um lado, se lhes exige que sejam autônomas, capazes de regular a sua aprendizagem e o trabalho escolar, gerir o seu próprio trajeto (SARMENTO, 2011), por outro, os espaços e tempos de exercício da autonomia são exíguos e a integração das crianças no universo escolar está amplamente regulada e avaliada pelos adultos que as controlam e dirigem.

A avaliação e a disponibilidade do aluno para ser avaliado são outros dos traços marcantes da cultura escolar e do ofício de aluno. A avaliação permite aferir o domínio que o aluno tem do currículo e identifica "os sinais exteriores de competência” (PERRENOUD, 1995, p. 138) e é sempre realizada em função de uma norma implícita ou explícita (PERRENOUD, 1989), seja relativa à conduta no contexto escolar, seja relativa à avaliação da performance e do mérito, cuja definição é sempre subjetiva e contextualizada, um julgamento social (DURU-BELLAT, 2002).

Conformidade do aluno às regras estabelecidas e às normas que regem a excelência escolar definem o ofício de aluno. Não basta, como refere Sirota (1993), dominar os conhecimentos e evidenciar competências cognitivas, é necessário também demonstrar que se tem um domínio apurado dos códigos interativos e das normas de comportamento, ou seja, conformismo e competência configuram o "ideal comportamental do bom aluno" (FELOUZIS, 1994).

Pelo que temos afirmado também se depreende que a forma escolar pressupõe e incentiva formas de poder e autoridade dos adultos que controlam a integração escolar dos alunos e que são fortemente assimétricas. A lógica eminentemente transmissiva que caracteriza o modelo dominante de escolarização tende a desvalorizar a cultura e os saberes das crianças e coloca no adulto a legitimidade da definição das regras, dos saberes e competências que devem ser interiorizados.

0 que pretendemos defender é que esses traços culturais que temos vindo a caracterizar influenciam, em contexto escolar, a relação das crianças com os adultos, em geral, e com o investigador, em particular. 
Nas investigações que temos desenvolvido junto a crianças, procuramos evitar atuações que nos conotem com um "adulto típico" (CORSAR0; MOLINARI, 2005) e despendemos tempo e esforços necessários para nos tornarmos uma "figura familiar" (MAYAL, 2005), porque investimos em uma relação continuada e próxima a fim de ganharmos a sua confiança (PUNCH, 2002).

Retomemos a investigação a que já aludimos no ponto anterior (E1). Em uma das fases da investigação, e no sentido de captarmos as representações dos alunos acerca da comunidade onde moram, solicitamos que nos indicassem quais os lugares da comunidade que frequentam e com que finalidades; no seguimento das conversas que fomos realizando, solicitamos, ainda, permissão para que, caso o entendessem, desenhassem uma planta da localidade onde moram, que assinalassem os locais que costumam frequentar nas diferentes atividades que realizam ao longo de um dia da semana típico e durante o fim de semana. 0 episódio que ocorreu com o Lucas $^{4}$ marca bem a posição que queremos defender:

Lucas: Hummmm... isto de fazer um desenho não vai correr nada bem, nada bem mesmo! Investigadora: Por que é que dizes isso? Não gostas de desenhar?

Lucas: Gosto. Mas parece que não sei desenhar...

Investigadora: Não sabes desenhar? Por que é que dizes isso? Olha conheço vários adultos que não sabem desenhar, incluindo eu, mas não conheço nenhum menino ou menina que não saiba... Por que é que dizes isso?

Lucas: a minha professora diz que eu sou um trapalhão, faço muita salganhada... (Diário de campo $^{5}, 2012$ ).

Esse excerto, retirado das notas de campo que realizamos durante o período de imersão na escola onde decorreu a investigação, demonstra bem como a lógica de avaliação e os critérios pelos quais se podem castrar a expressividade da criança. Não negligenciamos, no sentido de Punch (2002), que o fato de a investigação decorrer em contexto escolar influencia o processo de investigação, podendo coagir as crianças a assumirem o ofício de aluno e a mimetizarem, na relação que mantêm com o investigadoradulto, as relações de poder assimétricas que mantêm com o professor, não isolando o papel do contexto.

Nas experiências de investigação que temos desenvolvido e orientado são recorrentes, especialmente nas crianças em idade escolar, os episódios em que se sentem pressionadas para responder corretamente e a questão “o que eu disse está certo?” traduz a preocupação em corresponderem às expetativas dos adultos que as questionam, mas também revela como no seu quotidiano escolar imperam o controle e a avaliação em detrimento das oportunidades de expressão da identidade.

4- Os nomes próprios usados neste artigo são sempre fictícios.

5- Percebendo, de imediato, o desconforto do Lucas com a tarefa, optamos por parar a realização do desenho e lhe mostramos uma planta da localidade onde reside para que aí assinalasse os locais solicitados. Este exemplo também demonstra como o desempenho do ofício de aluno pode ser uma experiência social desqualificante e humilhante, como 0 demonstraram, nos anos 80, muito teóricos da sociologia crítica. Tais constatações, posteriormente, têm sido comprovadas por diversos autores entre os quais se situam, por exemplo, Dubet (1991). 
A necessidade de perceber a criança que está para além do aluno é uma das preocupações que está na gênese da Sociologia da Infância (MARCHI, 2010) e constitui uma temática de grande relevância para a formação de professores e educadores, porque permite reconhecer traços dos quotidianos infantis mediante o conhecimento que veiculam sobre as suas realidades sociais e culturais. Além disso, a lógica emancipatória que esta disciplina propõe na abordagem da infância faculta quadros interpretativos e estratégias metodológicas que permitem reconhecer as competências, saberes e visões do mundo infantis, bem como erigir as crianças como sujeitos de direitos nos processos educativos, respeitando e incorporando as suas múltiplas formas de expressão.

Mas poderão esses adultos que controlam o acesso às crianças influenciar os processos de investigação?

\section{Impacto dos gatekeepers no processo de investigação}

Os adultos que controlam o acesso à criança em contexto escolar - os gatekeepers de que falam, por exemplo, Corsaro e Molinari (2005) - são fundamentais e inultrapassáveis para nos garantirem a autorização no acesso, mas também para facilitarem a aceitação do investigador pelo grupo e facultarem informações fundamentais a respeito das organizações onde decorre a investigação, esclarecendo a sua estrutura, sistemas relacionais e organização pedagógica.

Por outro lado, e como refere Rayou (1999), os adultos que envolvem as crianças no espaço escolar são uma fonte de conhecimento complementar que podem iluminar as temáticas que estamos a analisar, permitindo construir um olhar mais esclarecido sobre os acontecimentos que analisamos; este olhar pressupõe incorporar as diferentes significações que adultos e crianças realizam sobre as suas ações objetivando-as, ou seja, integrando-as em uma "visão global" (BOURDIEU, 1989, p. 58). Nesse processo, o investigador tem de assumir-se como uma "testemunha modesta" (HARAWAY, 1997) que intervém nos contextos que estuda, abstraindo-se de tomar partido, procurando com que tanto a recolha de informação quanto a análise dos acontecimentos não sejam contaminadas por visões parciais de alguns atores que intervêm no campo que estuda.

Ora, o que defendemos neste contexto, e com base na nossa experiência de investigação com crianças no contexto da formação em educação, é que os adultos podem influenciar os processos de investigação colocando obstáculos e pressões de natureza diversa, na medida em que se lhes concede o poder de regular e controlar a participação das crianças no processo de investigação, subalternizando-se, frequentemente, a perspectiva destas em relação a essa participação.

Uma das questões mais debatidas nessa matéria releva dos procedimentos éticos utilizados no processo de construção do conhecimento sobre os universos infantis e remete para a desvalorização da "ontologia ética das crianças nos processos de construção de conhecimento acerca de si” (FERNANDES, 2016, p. 762) ou o não respeito pelo princípio da simetria ética com os adultos (CHRISTENSEN; PROUT, 2002). A observância de questões éticas é fundamental em qualquer agenda de investigação, mas torna-se mais imperativa quando se trata da investigação com os mais jovens para garantir que os seus "direitos, 
sentimentos e interesses" (CHRISTENSEN; PROUT, 2002, p. 493) sejam centrais e tão importantes quanto os dos adultos.

Para além de todas as questões éticas que perpassam uma conduta que procura garantir o respeito e a justiça, o consentimento informado é um dos que mais debates tem gerado e, não raramente, as investigações reservam às crianças o estatuto de "sujeitos desconhecidos da investigação, os quais estão desinformados acerca do facto de estarem a ser investigados, não lhes sendo sequer solicitado consentimento informado" (FERNANDES, 2016, p. 762), a pretexto, muitas vezes, de não se comprometer a sua espontaneidade e de se poder adotar uma "estratégia de entrada "reativa" no campo (CORSAR0, 2005, p. 448) que permita ao adulto despir-se do seu papel normativo e controlador na interação que estabelece com os mais novos. Ora, na prática, tal traduz-se pelo reconhecimento da superioridade ontológica dos adultos, para além de não se respeitarem os direitos de informação e consulta nas decisões que implicam as crianças.

Não negligenciamos, na linha de Morrow e Richards (1996), que o consentimento implica participação voluntária com base em informação pertinente e, no caso das crianças mais pequenas, podemos questionar em que medida a informação que lhes transmitimos as elucida acerca das implicações da sua participação, desconhecendo elas o próprio processo de investigação? Se as perspectivamos como atores sociais e sujeitos de direitos temos de lhes facultar as informações relevantes, e ajustadas à sua condição etária, dando-lhes a oportunidade para irem formulando o seu assentimento ao longo do processo e não apenas na fase inicial da investigação. Tal implica que o investigador não coloque nas crianças pressão para a participação e esteja preparado para renegociar os protocolos de investigação, não assumindo que o seu assentimento é algo irreversível no decurso do processo.

Rayou (1999) alerta-nos para outros tipos de desafios, pressões e obstáculos que os gatekeepers podem colocar ao processo de investigação, designadamente a influência que eles podem exercer nos objetivos de investigação delimitados pelo próprio investigador, as limitações que podem colocar à expressividade da criança no decurso do processo de investigação, impondo os seus pontos de vista ou, ainda, o fato de poderem assumir um papel de intrusos na relação que o investigador procura estabelecer com as crianças que estuda. Este excerto, retirado do diário de campo de formandas finalistas da licenciatura em educação de infância (estudo E2), ilustra exemplarmente algumas destas questões assinaladas pelo autor:

Chegou o momento de apresentarmos à educadora o nosso plano de investigação para estudarmos as perspetivas das crianças sobre as brincadeiras. Depois de semanas de leituras e várias conversas com a nossa orientadora, interessa-nos também pedir a opinião da educadora sobre a exequibilidade do projeto, uma vez que conhece o grupo de crianças.

Educadora: acho que vão pedir às crianças demasiado e elas vão-se cansar de falar sobre o mesmo... Conversas, desenhos, filmagens, dramatizações! Observá-las na casinha e no recreio dá para perceberem. Eu posso dizer-vos ao que elas gostam de brincar, onde costumam brincar e com quem, conheço-as muito bem... (Diário de campo da Ana, Sofia e Eva, 2005).

Desde logo esta perspectiva enuncia, na nossa opinião, uma posição privilegiada do observador-adulto em relação ao observado-criança, reconhecendo que aquilo que ele 
observa é "mais real e objetivo" (DEROUET, 1991, p. 65) do que aquilo que as crianças pensam e sentem e que a realidade é objetiva e independente da consciência que dela formam as crianças, que, de alguma forma, aqui não são perspectivadas enquanto atores sociais competentes para expressarem os seus pontos de vista e explicitarem as intenções, razões e motivos dos seus comportamentos e dos comportamentos daqueles com que interagem.

Enuncia, ainda, por parte do adulto, uma forma de ventriloquismo etnográfico, sugestiva expressão de Clifford Geertz que James (2007) recupera para dar conta de um processo em que falamos pelo outro, ou seja, falamos de uma cultura como se entendêssemos as formas de pensar e de agir sem que a voz dos nativos tenha sido ouvida. É também uma manifestação do adultocentrismo que está aqui presente, pois o adulto antecipa respostas, projeta ideias e interpretações, em suma, racionaliza a experiência infantil sem que para tal a criança seja perspectivada como a informante válida e legítima. É também, deste ponto de vista, uma forma de afirmação do poder e da autoridade do adulto na definição e interpretação das situações em contexto educativo e uma subalternização do papel da criança nesse processo.

É ainda uma postura que infantiliza as crianças, ignora a complexidade dos atos que elas desenvolvem (neste caso a brincadeira) e veicula uma perspectiva tendencialmente homogeneizadora do grupo, desconsiderando as singularidades e pertenças culturais diversas, processos de socialização igualmente distintos. Escutar as vozes das crianças permite perceber que elas, nas brincadeiras, se apropriam criativamente dos valores, normas e regras que lhes são transmitidos pelos adultos - realizam uma reprodução interpretativa desse mundo, no sentido de Corsaro (1997) - e permite, ainda, captar as suas formas de significarem esse mundo e de lidarem com as estruturas que aí condicionam a sua integração (FERREIRA, 2006).

Mas até que ponto é o adulto competente para entender as manifestações das culturas infantis? Tomando como exemplo as culturas de consumo das crianças, influenciadas pelos media, propomos refletir em seguida alguns dos desafios que colocam à prova a competência do investigador quando imerge nos universos infantis.

\section{Desafios à competência do investigador}

Os quotidianos infantis estão hoje colonizados pelas tecnologias e quem lida com os mais jovens percebe que o seu universo simbólico e as suas referências culturais se têm vindo a modificar por influência de uma cultura mediática cada vez mais omnipresente.

Um dos traços mais impressivos da presença da globalização nos universos infantis tem sido a inserção compulsiva dos mais jovens nos mercados de consumo. A globalização das atividades econômicas e dos mercados, o consumo alargado de produtos globais, a revolução tecnológica e a consequente globalização da comunicação eletrônica têm contribuído para construir, em diferentes sociedades, uma cultura tendencialmente homogeneizadora que produz representações globais porque se torna um "mundo feito a partir da MTV, do MacDonalds e de MCtM's" (AXFORD, 2000, p. 244), ainda que seja um processo atravessado por desigualdades profundas e navegue a desiguais velocidades em diferentes contextos sociais. 
O excerto seguinte, recolhido por uma formanda numa escola infantil (estudo E3), apresenta de forma paradigmática este movimento de transformação das crianças em consumidoras, nos contextos sociais de globalização em que vivemos:

Sentadas à volta da mesa, quatro meninas da sala dos 5 anos conversam enquanto admiram a roupa que uma delas tem vestida.

Rita: A minha mãe também vai-me comprar uns sapatos joques (Geox).

Maria: A mim a minha mãe também vai-me comprar umas calças e um casaco da beton (United Colors of Benetton).

Sofia: Eu também já pedi à minha mãe uma blusa da ieló quiti (Hello Kitty), mas ela diz que é muito dinheiro, que só pode comprar nos chineses! (Diário de campo da Mariana, 2011).

Quando a nota de campo é apresentada, no contexto da disciplina em que foi registrada, Mariana assume a sua estranheza em relação aos aspectos focados no diálogo entre as meninas, a sua incompetência em perceber o vocabulário utilizado e esta dimensão da moda enquanto artefacto cultural presente no imaginário infantil. Ora, esse exemplo de incompreensão das vozes das crianças, que se multiplicam na investigação que nós adultos realizamos com elas, desafia o investigador a conhecer o universo de produções culturais para a infância, no sentido de compreender a influência destas na linguagem, no imaginário, nas culturas de pares e nas identidades infantis.

A transformação dos mais jovens em consumidores potenciais dos mesmos produtos em diferentes latitudes influencia as culturas infantis, mas "os guiões contidos nos produtos mediáticos e tecnológicos são filtrados pelas condições sociais de recepção e reescritos pelas crianças, em função das suas condições sociais de pertença” (SARMENTO, 2011, p. 596).

0 exemplo vivenciado por Mariana ilustra, exemplarmente, como o reconhecimento da agência das crianças não autoriza a secundarização do peso das estruturas sociais, em termos de pertença social e das condicionantes culturais que produzem as identidades de gênero. Em suma, é um exemplo que simboliza a complexidade do empreendimento de entender as crianças, neste caso, as suas culturas de pares e os desafios que neste domínio se colocam ao adulto enquanto outsider cultural.

0 exemplo serve, ainda, para refletir criticamente acerca da competência do investigador em representar, através do processo de recolha e interpretação, as vozes das crianças, questionando em que medida o que entendemos sobre elas se aproxima daquilo que elas querem significar (JAMES, 2007; SPYROU, 2011). Para esses autores, o trabalho de tradução, mediação e interpretação das vozes infantis coloca questões relevantes não só de representação, mas também de autoria.

Entre as questões de representação, James (2007) adverte para as armadilhas do guião "positivista" (p. 263) que consiste em considerar que aquilo que é desocultado junto de crianças socialmente situadas se pode aplicar ao universo infantil como um todo, negligenciando os contextos reais de pesquisa em que as vozes das crianças são produzidas, bem como os desequilíbrios de poder que as moldam.

As descrições e interpretações que o investigador realiza sobre a linguagem e imaginários infantis refletem a visão do autor e não dos sujeitos que observa, pois é o 
investigador que define quem são as vozes que se assumem como proeminentes e quais os recortes semânticos valorizados (JAMES, 2007).

Spyrou (2011) questiona mesmo se nesse processo de recolha e análise da informação não serão as categorias semânticas do adulto valorizadas em detrimento da semântica das próprias crianças, condição que, a verificar-se, traduz o entendimento do investigador sobre as crianças e não as significações destas (SPYROU, 2011, p. 158).

É nesse sentido que uma das questões que discutimos com os formandos remete para a necessidade de produzirem registros de observações (diretas e indiretas) fidedignos em relação à forma como foram produzidos, como no exemplo apresentado, reproduzindo fielmente a estrutura sintática e semântica das falas das crianças. Obviamente que esse truque do ofício não evita, por si só, que ao nível dos relatórios de pesquisa as vozes das crianças sejam utilizadas de forma acrítica e descontextualizada, pois, como refere Spyrou (2011, p. 159), “o uso comum de citações para destacar as vozes e as perspetivas das crianças só pode servir o propósito pretendido quando estas vozes estão totalmente situadas nos campos discursivos do poder que as produzem", ou seja, estão referenciadas aos contextos históricos e socioculturais que limitam e moldam a sua linguagem e formas de expressão.

\section{Considerações finais}

Ao longo deste artigo, discutimos alguns dos desafios e responsabilidades que se colocam ao investigador quando tem em consideração as crianças como informantes qualificados e privilegiados acerca dos seus contextos de vida e formas de entenderem o mundo.

Salientamos algumas das nuances de que se reveste o processo de alunização das crianças e a forma como uma cultura de obediência a valores e práticas de avaliação pode condicionar a expressão da identidade da criança e a relação com o próprio investigador.

Alguns dos dados produzidos no âmbito de pesquisas empíricas permitem-nos refletir o impacto das perspectivas adultocêntricas e paternalistas que acentuam a imaturidade e a incompetência das crianças. Percebemos que essas perspectivas, socialmente vulgarizadas, podem influenciar a imagem que as crianças formulam sobre si próprias, inibindo o exercício dos seus direitos, designadamente os de opinião e expressão, nas famílias e escola. Nesta, o desequilíbrio de poderes que a carateriza e a afirmação da autoridade dos adultos podem legitimar a desvalorização da voz das crianças a pretexto de um deficit de racionalidade, competência e maturidade para explicitarem as intenções, razões e motivos que justificam a sua ação e interação sociais.

Mas a investigação com crianças também coloca sob suspeita o etnocentrismo do próprio investigador, e os seus pressupostos, na análise que realiza sobre as manifestações das culturas infantis, relativamente às quais o investigador-adulto é um estranho. Neste contexto, refletimos alguns dos desafios que colocam à prova a competência do investigador na compreensão e interpretação dos referenciais caracterizadores dessas culturas.

Uma questão central que privilegiamos na formação de professores consiste em conscientizar os formandos que para um entendimento compreensivo da infância (JAMES; 
JAMES, 2009) torna-se imperativo estabelecer diálogos conceituais (SIROTA, 2005) e construir opções teóricas ecléticas baseadas em uma articulação com as diferentes ciências sociais que procuram compreender o ponto de vista das crianças sobre si e sobre o mundo.

Do ponto de vista metodológico, a investigação com crianças exige a recusa de monoteísmos metodológicos (BOURDIEU, 1989) e a opção por combinatórias metodológicas que permitam captar a pluralidade de formas de comunicação da criança e garantir que todas possam fazer ouvir a sua voz, mesmo as que, por diferentes e variados motivos, "têm pouca ou nenhuma fala" (SPYROU, 2016, p. 10).

Ainda que nos casos analisados ao longo deste artigo as crianças tenham desempenhado o papel de sujeitos e não de participantes nas pesquisas, a opção por métodos participativos (GROUNDWATER-SMITH; DOCKETT; BOTTRELL, 2015; BRADBURYJONES; TAYLOR, 2015) em que as agendas de pesquisa são construídas com - como co-investigadoras - e pelas crianças - como investigadoras principais - oferece novas possibilidades de entendimento dos universos infantis a partir da perspectiva dos seus principais protagonistas, ainda que tal empreendimento coloque à investigação questões conceituais, éticas e metodológicas acrescidas.

Este constitui um desafio que gostaríamos de assumir em investigações futuras, no sentido de ultrapassarmos as limitações decorrentes de processos de pesquisa, na linha dos que aqui apresentamos, que traduzem o entendimento e a afirmação do poder do adulto na decifração das significações infantis em função de traços que ele, unilateralmente, elege para caraterizar os universos culturais das crianças.

\section{Referências}

ARIÈS, Philippe. L'enfant et la vie familiale sous l'Ancien Régime. Paris: Plon, 1960.

AXFORD, Barrie. Globalisation. In: BROWNING, Gary; HALCLI, Abigail; WEBSTER, Frank (Ed.). Understanding contemporary society: theories of the present. London: Sage, 2000. p. 238-252.

BARDIN, Lawrence. Análise de conteúdo. Lisboa: Edições 70, 1979.

BARROSO, João. Políticas educativas e organização escolar. Lisboa: Universidade Aberta, 2005.

BECK, Ulrich. A reinvenção da política. Rumo a uma teoria da modernização reflexiva. In: BECK, Ulrich; GIDDENS, Anthony; LASH, Scott. Modernização reflexiva. Oeiras: Celta, 2000. p. 1-51.

BOURDIEU, Pierre. 0 poder simbólico. Lisboa: Difel, 1989.

BRADBURY-JONES, Caroline; TAYLOR, Julie. Engaging with children as co-researchers: challenges, counter-challenges and solutions. International Journal of Social Research Methodology, London, v. 18, n. 2, p. 161-173, 2015.

BRANNEN, Julia; O’BRIEN, Margaret. Children in families. London: Falmer, 1996. 
CARDONA, Maria João. Educação pré-escolar ou pedagogia da educação de infância? fundamentos e conceções subjacentes. Nuances, São Paulo, v. 20. n. 21, 144-162, 2011.

CHRISTENSEN, Pia; PROUT, Alan. Working with ethical symmetry in social research with children. Childhood, London, v. 9, n. 4, p. 477-497, 2002.

CORSAR0, William. A entrada no campo, aceitação e natureza da participação nos estudos etnográficos com crianças pequenas. Educação e Sociedades, Campinas, v. 26, n. 91, maio/ago. p. 443-464, 2005.

CORSARO, William. The sociology of childhood. Thousand Oaks: Pine Forge, 1997.

CORSARO, William; MOLINARI, Luisa. Entrando e observando nos mundos da criança: uma reflexão sobre a etnografia longitudinal da educação de infância em Itália. In: CHRISTENSEN, Pia; JAMES, Alison (Org.). Investigação com crianças: perspectivas e práticas. Porto: Escola Superior de Educação de Paula Frassinetti, 2005. p. 191- 213.

DEROUET, Jean Louis. Une sociologie qui prend au sérieux la rationalité des acteurs... Revue Française de Pédagogie, Lyon, n. 95, p. 65-66, avr./juin. 1991.

DUBET, François. Les lycéens. Paris: Du Seuil, 1997.

DUBET, François; MARTUCCELLI, Danilo. A l'école: sociologie de l'expérience scolaire. Paris: Du Seuil, 1991.

DURU-BELLAT, Marie. Les inégalités sociales à l'école: genèse et mythes. Paris: PUF, 2002.

ESTEVES, Manuela. Análise de conteúdo. In: LIMA, Jorge Ávila; PACHECO, José Augusto (Org.). Fazer investigação: contributos para a elaboração de teses e dissertações. Porto: Porto Editora, 2006. p. 105-126.

FELOUZIS, Georges. Le collège au quotidien. Paris: PUF, 1994.

FERNANDES, Natália. Ética na pesquisa com crianças: ausências e desafios. Revista Brasileira de Educação, Rio de Janeiro, v. 21, n. 66, p. 759-779, jul./set. 2016.

FERREIRA, Manuela. "- tá na hora d'ir pr'à escola!"; "- eu não sei fazer esta, senhor Professor!" Ou... brincar às escolas na escola (ji) como um modo das crianças darem sentido e negociarem as relações entre a família e a escola. Revista Interacções, Lisboa, n. 2, p. 27-58, 2006.

FORMOSINHO, João. Organizar a escola para o sucesso educativo. In: CRSE, Medidas que promovam o sucesso educativo. Lisboa: Ministério da Educação, 1988. p. 123-146.

GRAUE, Elisabeth; WALSH, Daniel. Investigação etnográfica com crianças: teorias, métodos e ética. Lisboa: Fundação Calouste Gulbenkian, 2003.

GROUNDWATER-SMITH, Susan, DOCKETT, Sue; BOTTRELL, Dorothy. Participatory research with children and young people. Los Angeles: Sage, 2015. 
HARAWAY, Donna. Modest witness at second millenium. Femaleman@__Meets_Oncomouse ${ }^{\mathrm{TM}}$ : feminism and technoscience. New York: Routledge, 1997.

JAMES, Adrian; JAMES, Alison. Key concepts in childhood studies. London, Sage, 2009.

JAMES, Alison. Giving voice to children's voices: practices and problems, pitfalls and potentials. American Anthropologist, Arlington, v. 109, n. 2, p. 261-272, 2007.

LAHIRE, Bernard. Sucesso escolar nos meios populares: as razões do improvável. São Paulo: Ática, 1997.

LEAL, João. Diários de Campo: modos de fazer, modos de usar. In: ALMEIDA, Sónia Vespeira; CACHAD0, Rita (Ed.). Arquivos dos antropólogos. Lisboa: Palavrão, 2016. p. 143-154.

LIMA, Jorge Ávila. Por uma análise de conteúdo mais fiável. Revista Portuguesa de Pedagogia, Coimbra, v. 47, n. 1, 2013.

MARCHI, Rita. "O ofício de aluno" e o "ofício da criança": articulações entre a sociologia da educação e a sociologia da infância. Revista Portuguesa de Educação, Braga, v. 23, n. 1, p. 183-202, 2010.

MAULINI, Olivier; MEYER, Aline; MUGNIER, Cynthia. Forme scolaire d'apprentissage et pratiques pédagogiques (Carnets de Sciences de L'éducation). Université de Genève. Faculté de Psychologie et des Sciences de L'éducation, 2014.

MAULINI, Olivier; PERRENOUD, Philippe. La forme scolaire de l'éducation de base: tensions internes et évolutions. In: MAULINI, Olivier; MONTANDON, Cleopatre (Ed.). Les formes de l'éducation: variété et variation. Bruxelles: De Boeck, 2005. p. 147-168.

MAYALL, Berry. Conversas com crianças: trabalhando com problemas geracionais. In: CHRISTENSEN, Pia; JAMES, Alison (Org.). Investigação com crianças: perspectivas e práticas. Porto: Escola Superior de Educação de Paula Frassinetti, 2005. p. 123-141.

MORROW, Virginia. Ethical dilemmas in research with children and young people about their social environments. Children's Geographies, Oslo, v. 6, n. 1, p. 49-61, 2008.

MORROW, Virginia; RICHARDS, Martin. The ethics of social research with children: an overview. Children and Society, New York, v. 10, n. 2, p. 90-105, 1996.

PALOS, Ana Cristina; SOUSA, Francisco. Azorean children's engagement with rural communities in the age of globalization: folkore, resistence or global citizenship on a small scale? Aberystwyth (Wales): [s. n.], 2012. Paper presented at the international Conference a Child's World - Working Together for a Better Future.

PERRENOUD, Philippe. Métier d'élève et sens du travail scolaire. Paris: ESF, 1995.

PERRENOUD, Philippe. Vers une sociologie de l'évaluation. Bulletin de L'Association des Enseignants et Chercheurs en Éducation, Paris, n. 6, p. 19-31, 1989. 
PUNCH, Samantha. Research with children: the same or different from research with adults? Childhood, London, v. 9, n. 3, p 321-341, 2002.

QVORTRUP, Jens. Infância e política. Cadernos de Pesquisa, São Paulo, v. 40, n. 141, p. 777-792, set./ dez, 2010.

RAYOU, Patrick. La grande école: approche sociologique des compétences enfantines. Paris: Presses Universitaires de France, 1999.

SARMENTO, Manuel Jacinto. A reinvenção do ofício de criança e aluno. Atos de Pesquisa em Educação, Florianópolis, v. 6, n. 3, p. 581-602, set./dez. 2011.

SARMENTO, Manuel Jacinto. Gerações e alteridade: interrogações a partir da sociologia da infância. Educação \& Sociedade, Campinas, v. 26, n. 91, p. 361-378, maio/ago. 2005.

SARMENTO, Manuel Jacinto. Infância contemporânea e educação infantil: uma perspectiva a partir dos direitos da criança. In: SALMAZE, Maria Aparecida; ALMEIDA, Ordália Alves (Org.). Primeira infância no século XXI: direitos de viver, brincar, explorar e conhecer o mundo. Campo Grande: Oeste/OMEP Brasil, 2013. p. 131-148.

SIROTA, Régine. Emergência de uma sociologia da infância: evolução do objeto e do olhar. Cadernos de Pesquisa, São Paulo, n. 112, p. 7-31, mar. 2001.

SIR0TA, Régine. Le métier d'élève. Revue Française de Pédagogie, Lyon, v. 104, n. 1, p. 85-108, 1993.

SIROTA, Régine. Petit objet insolite ou champ constitué, la sociologie de l'enfance est-elle encore dans les choux? In: SIROTA, Régine (Org.). Éléments pour une sociologie de l'enfance. Rennes: PUR, 2006. p. 13-34.

SOUSA, Francisco; PALOS, Ana Cristina. Formar professores investigadores: que margem de manobra no plano curricular? In: COLÓQUIO LUSO BRASILEIRO DE CURRÍCULO, 7., 2014, Braga e LUSO AFROBRASILEIRO DE QUESTÕES CURRICULARES, 1., 2014, Braga. Atas... Braga: CIEd. Universidade do Minho, 2014. p. 672-678.

SPYROU, Spyros. Researching children's silences: exploring the fullness of voice in childhood research. Childhood, London, v. 23, n. 1, p. 7-21, 2016.

SPYROU, Spyros. The limits of children's voices: from authenticity to critical, reflexive representation. Childhood, London, v. 18, n. 2, p. 151-165, 2011.

STENHOUSE, Lawrence. An introduction to curriculum research and development. London: Heinemann, 1975.

TOMÁS, Catarina. As culturas da infância na educação de infância: um olhar a partir dos direitos da criança. Revista Interacções, Lisboa, n. 32, p. 129-144, 2014. 
VINCENT, Guy; LAHIRE, Bernard; THIN, Daniel. Sur I'histoire et la théorie de la forme scolaire. In: VINCENT, Guy (Dir.). L'éducation prisonnière de la forme scolaire? Lyon: Presses Universitaires de Lyon, 1994. p. 11-48.

Revisado em: 25.10.2017

Aprovado em: 29.11.2017

Ana Cristina Palos é doutora em ciências da educação, especialidade em sociologia da educação, e investigadora no Centro Interdisciplinar de Ciências Sociais - Pólo da Universidade dos Açores (CISC.NOVA.UAc/CISC.Uac). 